11

\title{
Генерация сверхширокополосного электромагнитного излучения вакуумным фотодиодом с анодом на входном сапфировом окне
}

\author{
(C) А.В. Потапов, ${ }^{1}$ Е.В. Заволоков, ${ }^{1}$ А.А. Кондратьев, ${ }^{1}$ Н.А. Пхайко, ${ }^{1}$ И.А. Сорокин, ${ }^{1}$ Б.Г. Гончаренко, ${ }^{2}$ \\ В.А. Лузанов, ${ }^{2}$ В.Д. Салов ${ }^{2}$
}

${ }^{1}$ Госкорпорация „Росатом“, Российский федеральный ядерный центр - Всероссийский научно-исследовательский институт технической физики им. акад. Е.И. Забабахина,

456770 Снежинск, Россия

${ }^{2}$ Фрязинский филиал Института радиотехники и электроники им. В.А. Котельникова РАН,

141190 Фрязино, Россия

e-mail: dep5@vniitf.ru, goncharenko_b@mail.ru

Поступило в Редакцию 30 июля 2020 г.

В окончательной редакции 7 сентября 2020 г.

Принято к публикации 9 сентября 2020 г.

\begin{abstract}
Проведены исследования генерации сверхширокополосного электромагнитного излучения вакуумным фотодиодом с плоским сурьмяно-цезиевым фотокатодом. Анодом фотодиода являлся набор тонких алюминиевых полосок, нанесенных на входное сапфировое окно. Инициирование эмиссии электронов с фотокатода производилось излучением второй гармоники $(\lambda=385 \mathrm{~nm})$ титан-сапфировой лазерной системы с длительностью импульса $\sim 200 \mathrm{fs}$. Выполнены измерения напряженности электрической составляющей электромагнитного излучения при изменении напряжения на межэлектродном зазоре от 13 до $140 \mathrm{kV}$.
\end{abstract}

Ключевые слова: сверхширокополосное электромагнитное излучение, сурьмяно-цезиевый фотокатод, сапфир.

DOI: 10.21883/JTF.2021.03.50530.238-20

\section{Введение}

В работах [1,2] был предложен способ генерации сверхширокополосных (СШП) импульсов электромагнитного излучения (ЭМИ) вакуумным фотодиодом. Электроны, эмитированные с фотокатода при наклонном падении оптического или рентгеновского излучения, ускоряются электрическим полем, приложенным между анодом и фотокатодом, проходят через анодную сетку и создают излучающий дипольный слой над анодом. Этот способ генерации впервые был подтвержден экспериментально в работе [3]. Был разработан экспериментальный образец генератора СШП ЭМИ с металлическим катодом и анодом в форме параболоида вращения и лазер-плазменным источником инициирующего излучения [4]. Однако лазер-плазменный источник излучения имеет низкую эффективность преобразования лазерного излучения в фотоэлектроны. Кроме того, технологически сложно изготовить фотодиод с такой формой электродов и межэлектродным зазором несколько миллиметров.

Была разработана другая конструкция генератора СШП ЭМИ, в которой был использован сурьмяноцезиевый плоский фотокатод и сетчатый анод [5]. Для инициирования эмиссии электронов с такого фотокатода используется лазерное излучение видимого диапазона пико- или субпикосекундной длительности (квантовая эффективность фотокатода составляет $\sim 15 \%$ на длине волны $400 \mathrm{~nm}$ второй гармоники титан-сапфировой лазерной системы).
Недостатком конструкции с проволочным анодом является нагрев анодной сетки ускоренными электронами в режиме генерации пачек импульсов большой длительности. В результате теплового расширения проволочек происходит изменение размера межэлектродного зазора вплоть до касания проволочками фотокатода. По этой причине были разработаны другие конструкции вакуумных фотодиодов. Следует отметить, что генерация СШП ЭМИ происходит не только над анодной сеткой, но и при движении электронов в анод-катодном зазоре. Это излучение может быть выведено из межэлектродного зазора через торец [6] или между параллельными анодными проводниками, расположенными перпендикулярно направлению распространения волны эмиссии фотоэлектронов вдоль катода [7]. Значительное увеличение массы анода за счет использования пластин вместо проволочек [7] позволило существенно уменьшить скорость нагрева анода и увеличить длительность непрерывной генерации.

В новой конструкции анодом является набор тонких металлических полосок, нанесенных на входное сапфировое окно. Сапфир обладает высокой теплопроводностью и обеспечивает отвод тепла от анода. Кроме того, такая конструкция позволяет обеспечить хорошую однородность ускоряющего электрического поля при размере межэлектродного зазора менее миллиметра, что необходимо для увеличения ширины спектра и характерной частоты ЭМИ.

В настоящей работе приведены результаты экспериментальных исследований генерации СШП ЭМИ ваку- 
умным фотодиодом с анодом на входном сапфировом окне.

\section{1. Фотоэмиссионный излучатель}

Фотоэмиссионный излучатель состоит из плоского фотокатода диаметром $9 \mathrm{~cm}$, размещенного внутри металлического корпуса, и параллельного ему входного окна, выполненного из сапфирового диска. На сапфир методом фотолитографии нанесен анод, состоящий из алюминиевых полосок толщиной $0.8 \mu \mathrm{m}$ и шириной $60 \mu \mathrm{m}$, расположенных с шагом $300 \mu \mathrm{m}$. Расстояние между фотокатодом и окном равно $0.3 \mathrm{~cm}$. На корпусе излучателя находится высоковольтный разъем, соединенный с катодом отрезком коаксиального волновода с волновым сопротивлением $75 \Omega$.

Для формирования анодной сетки производилось напыление алюминиевой пленки на сапфир. Был изготовлен позитивный фотошаблон на основе пленок окиси железа. Фоторезист наносился на алюминиевую пленку на центрифуге при скорости 2000 оборотов в минуту. В качестве проявителя использовался водный раствор щелочи КОН. Для травления алюминия использовался раствор, состоящий из смеси ортофосфорной, азотной и уксусной кислот.

В качестве материала корпуса выбрана нержавеющая сталь 08X18Н10Т вакуумной плавки. Использовалась технология проверки заготовок стали для отбраковки образцов, имеющих поры, возникшие при прокатке. Детали корпуса после их изготовления подвергались дополнительной механической обработке - шлифовке и полировке внутренних поверхностей корпуса. Производилась химическая очистка деталей, промывка с воздействием ультразвука и обезгаживающий отжиг. Для достижения наилучших вакуумных условий был выбран высоковольтный изолятор, изготовленный из алундовой керамики, не взаимодействующей с цезием.

В качестве подложки фотокатода использовались полированные диски из стали марки 12Х18Н10Т. Первоначально диски полировались алмазной пастой. Было обнаружено сильное шаржирование поверхности частицами алмаза, которые являются источниками автоэлектронной эмиссии и ухудшают электрическую прочность вакуумного межэлектродного зазора. Была отработана финишная полировка водной суспензией на основе окиси церия, которая применяется для полировки стекла. Шаржирование поверхности окисью церия устранялось травлением в соляной кислоте. Все органические загрязнения и частицы удалялись кипячением в растворе щелочи $\mathrm{KOH}(10 \%)$ и ультразвуковой обработкой в изопропиловом спирте. После химической очистки следовал высокотемпературный отжиг в вакуумной печи для удаления адсорбированных газов.

На подложке был сформирован сурьмяно-цезиевый фотокатод. Для формирования фотокатода была разработана технология напыления сурьмы в отдельной уста- новке с переносом в атмосфере аргона с последующей активацией цезием после откачки. Разработан режим отгонки избыточного цезия при температуре $150^{\circ} \mathrm{C}$ c контролем фотоэмиссии. Сохранению равновесия цезия способствует высокий вакуум, достигаемый в излучателе при откачке до $10^{-11}$ Torr и поддерживаемый встроенным магниторазрядным насосом. Измеренная квантовая эффективность изготовленного фотоэмиссионного излучателя составила 14 и 5\% на длине волны 405 и $525 \mathrm{~nm}$ соответственно.

Оценим нагрев входного окна при генерации последовательности импульсов. Коэффициент теплопроводности сапфира при температуре $100^{\circ} \mathrm{C}$ равен $\kappa \approx 26 \mathrm{~W} /(\mathrm{m} \cdot \mathrm{K})$, теплоемкость $C_{p} \approx 900 \mathrm{~J} /(\mathrm{kg} \cdot \mathrm{K})$, плотность $\rho \approx 4000 \mathrm{~kg} / \mathrm{m}^{3}$ [8]. Полный пробег электрона с энергией $100 \mathrm{keV}$ в сапфире составляет $0.2 \mathrm{~kg} / \mathrm{m}^{2}$ [9], соответственно выделение энергии происходит в слое толщиной $l \sim 50 \mu \mathrm{m}$ (пробег электронов значительно превышает толщину анодных полосок, поэтому основное выделение энергии происходит в сапфире), что приводит к нагреву сапфира в этой области за один импульс на величину $\Delta T=\varepsilon_{0} U^{2} /\left(2 h \rho l C_{p}\right)$. Для межэлектродного зазора $h=0.3 \mathrm{~cm}$ при напряжении $U=100 \mathrm{kV}$ получим $\Delta T \approx 0.08 \mathrm{~K}$. Глубина прогрева сапфира за счет теплопроводности в течение времени $\Delta t$ равна

$$
\Delta x \sim \sqrt{\frac{\kappa \Delta t}{\rho C_{p}}} .
$$

Если $\Delta x$ меньше, чем толщина окна, изменение температуры прогретого слоя сапфира при воздействии с частотой $v$ равно

$$
\Delta T \sim \frac{\varepsilon_{0} U^{2}}{2 h} \frac{v \Delta t}{\rho C_{p} \Delta x} \sim \frac{\varepsilon_{0} U^{2} v}{2 h} \sqrt{\frac{\Delta t}{\rho C_{p} \kappa}} .
$$

В качестве примера: при частоте следования импульсов $v=100 \mathrm{kHz}$, напряжении питания $U=50 \mathrm{kV}$, межэлектродном зазоре $h=0.3 \mathrm{~cm}$ за одну секунду изменение температуры окна составит $\Delta T \approx 38 \mathrm{~K}$. Толщина прогретого слоя при этом составит $\Delta x \approx 0.26 \mathrm{~cm}$.

\section{2. Постановка эксперимента}

Генерация СШП ЭМИ производилась в безэховой камере, которая представляет собой металлический бокс размером $6.3 \times 3.6 \times 3 \mathrm{~m} \quad$ (длина $\times$ ширина $\times$ высота), внутренняя поверхность которого покрыта радиопоглощающим материалом для предотвращения воздействия отраженного от стен излучения на средства диагностики ЭМИ. Импульсное напряжение отрицательной полярности с длительностью импульса на полувысоте $\sim 4 \mathrm{~ns}$ подавалось на фотокатод излучателя от генератора импульсного напряжения (ГИН). Значение выходного напряжения ГИН может плавно изменяться от $\sim 10$ до $\sim 100 \mathrm{kV}$. Измерение выходного напряжения ГИН 


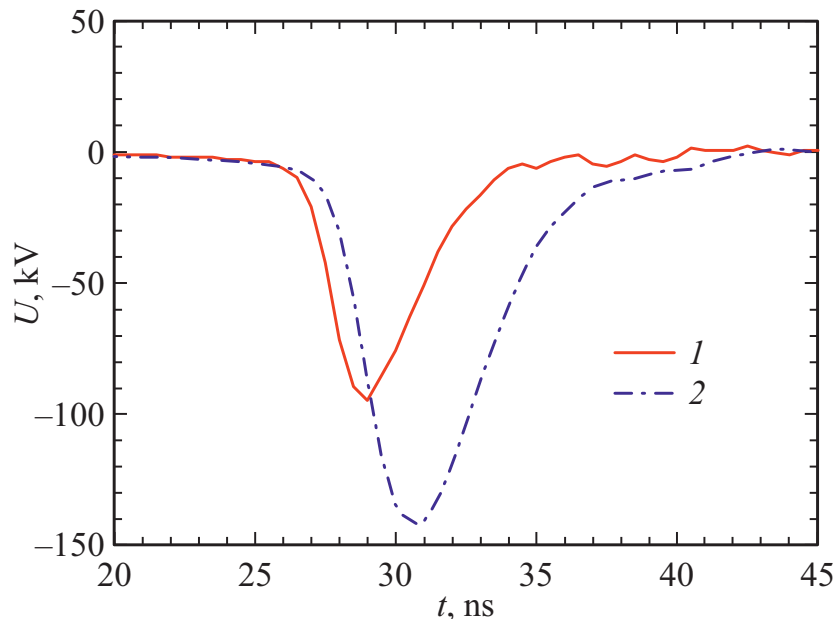

Pис. 1. Напряжение ГИН: 1 - на резистивной нагрузке $75 \Omega$ и 2 - на емкостной нагрузке, полученное решением уравнения (1) для значения $C=19 \mathrm{pF}$.

производилось резистивным делителем на согласованной резистивной нагрузке величиной $75 \Omega$. На рис. 1 приведена осциллограмма, полученная для максимального выходного напряжения ГИН.

Электрическая емкость фотодиода с межэлектродным зазором $0.3 \mathrm{~cm}$ составляет $C \approx 19 \mathrm{pF}$. Напряжение $U_{C}$ на емкости $C$, являющейся нагрузкой длинной линии (соединительного кабеля) с волновым сопротивлением $R$, есть сумма напряжений падающей $U_{f}$ и отраженной $U_{r}$ волн, распространяющихся по линии к нагрузке и от нее. Ток нагрузки $I_{C}=d q / d t=C d U_{C} / d t$ равен сумме токов падающей $U_{f} / R$ и отраженной $-U_{r} / R$ волн. Исходя из этого, напряжение на нагрузке может быть определено решением уравнения

$$
R C \frac{d U_{C}}{d t}=-U_{C}+2 U_{f}, U_{c}\left(t_{0}\right)=U_{C 0}, t \geq t_{0}
$$

График $U_{C}(t)$ для случая максимального выходного напряжения ГИН приведен на рис. 1. Амплитуды напряжений на резистивной и емкостной нагрузках отличаются примерно в 1.5 раза. Так как прямые измерения амплитуды напряжения на анод-катодном зазоре не представляются возможными, далее используются расчетные значения. Расчетные значения напряжения могут быть завышены в случае, если ток эмиссии электронов с катода до прихода инициирующего лазерного излучения составляет значительную величину по сравнению c $U_{C} / R$.

Инициирование эмиссии электронов с поверхности фотокатода осуществлялось излучением второй гармоники $(\lambda=385 \mathrm{~nm})$ титан-сапфировой лазерной системы с энергией в импульсе $350 \ldots 400 \mu \mathrm{J}$ и длительностью импульса $\sim 200$ fs. Угол падения излучения на фотокатод был равен $45^{\circ}$. Производились синхронизация срабатывания лазерной системы и ГИН для обеспечения прихода лазерного излучения на фотокатод в момент максимума напряжения.

Измерения напряженности электрической составляющей поля ЭМИ проводились преобразователем электрического поля ИППЛ-Л, расположенным на расстоянии $r=5 \mathrm{~m}$ от излучателя в направлении зеркального отражения лазерного излучения от его входного окна. Преобразователь изготовлен и откалиброван во ФГУП ВНИИОФИ и имеет следующие параметры:

- коэффициент преобразования $0.34 \mathrm{~V} /(\mathrm{kV} / \mathrm{m})$;

- время нарастания переходной характеристики между уровнями 0.1-0.9 от установившегося значения $9.6 \mathrm{ps}$; - длительность переходной характеристики по уровню 0.5 от установившегося значения $2.5 \mathrm{~ns}$;

- границы погрешности измерений коэффициента преобразования при доверительной вероятности 0.95 составляют $\pm 10 \%$.

Регистрация сигналов производилась осциллографом с полосой пропускания $59 \mathrm{GHz}$ и частотой дискретизации $160 \mathrm{GHz}$. Соединение преобразователя ИППЛ-Л с осциллографом осуществлялось кабельной сборкой Rosenberger длиной $1 \mathrm{~m}$. В измерительном тракте также использовались аттенюаторы с рабочей полосой частот $65 \mathrm{GHz}$ и погрешностью на частотах до $40 \mathrm{GHz}$ не более $\pm 0.5 \mathrm{~dB}$.

\section{3. Результаты исследований}

На рис. 2,3 приведены осциллограммы импульсов электрической составляющей поля ЭМИ, полученные для минимального и максимального напряжения ГИН. Максимальная напряженность поля ЭМИ составила $E \approx 210 \mathrm{kV} / \mathrm{m}$, что соответствует электродинамическому потенциалу излучателя $\Phi=|E|_{\max } \cdot r \approx 1050 \mathrm{kV}$. Зависимость электродинамического потенциала от напряжения показана на рис. 4 в логарифмическом масштабе. Полученная зависимость имеет степенной вид $\Phi \propto U^{\alpha}$ с

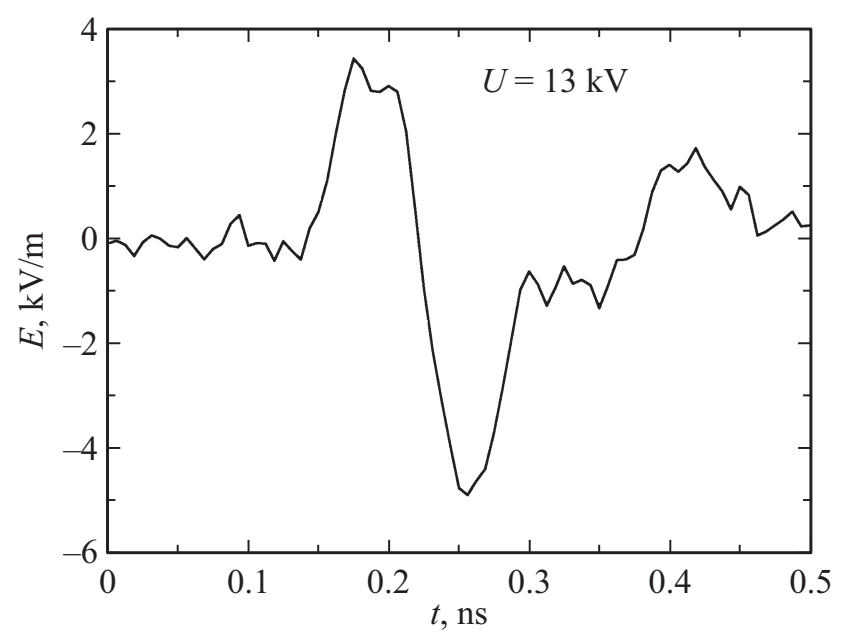

Рис. 2. Напряженность электрической составляющей поля ЭМИ при напряжении на межэлектродном зазоре $13 \mathrm{kV}$. 


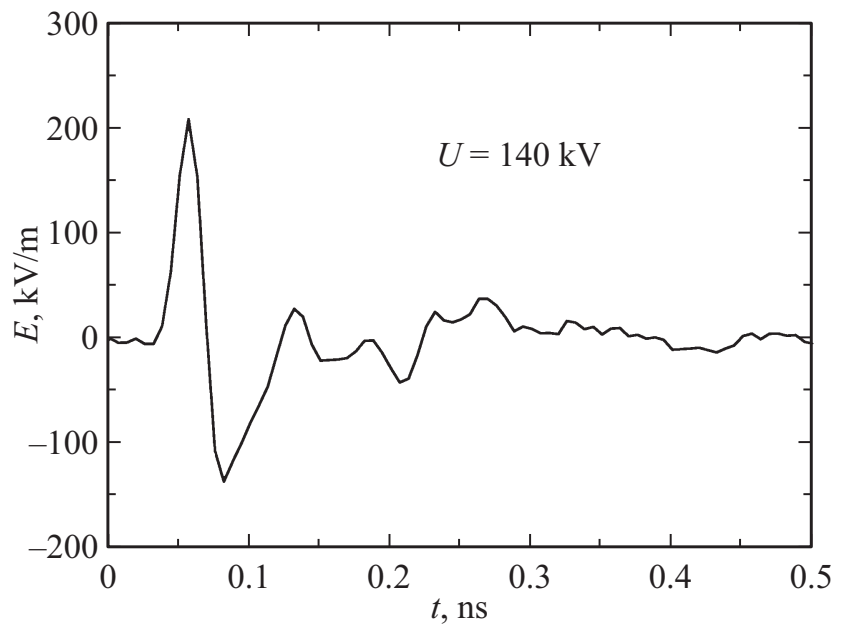

Рис. 3. Напряженность электрической составляющей поля ЭМИ при напряжении на межэлектродном зазоре $140 \mathrm{kV}$.

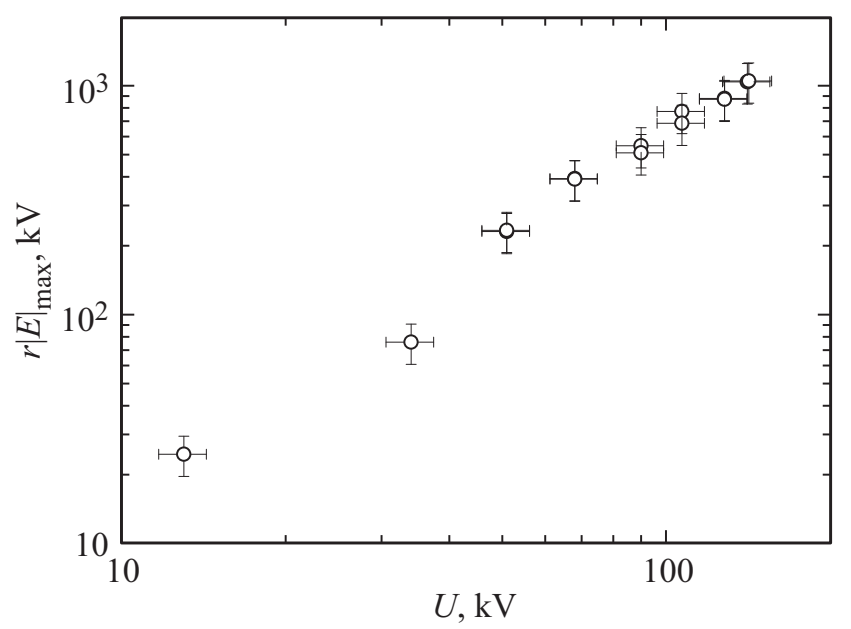

Рис. 4. Зависимость электродинамического потенциала излучателя от напряжения на межэлектродном зазоре.

показателем $\alpha \approx 1.6$ и отличается от теоретической [2], для которой $\alpha=2$.

Произведем оценку энергии излучения для случая максимального напряжения питания $U=140 \mathrm{kV}$. Электрическая емкость межэлектродного зазора $C=19 \mathrm{pF}$, соответственно запасенная энергия равна $Q_{C}=$ $=C U^{2} / 2=0.19 \mathrm{~J}$. Часть этой энергии расходуется на излучение. Для изотропного источника с электродинамическим потенциалом $\Phi=|E|_{\max } \cdot r \approx 1050 \mathrm{kV}$ полная пиковая мощность излучения $P_{m} \approx\left(E_{\max } \cdot r\right)^{2} / 30=$ $=3.7 \cdot 10^{10} \mathrm{~W}$, где $E_{\max }=210 \mathrm{kV} / \mathrm{m}-$ измеренная напряженность поля, $r=5 \mathrm{~m}-$ расстояние, на котором производилось измерение. Измеренная зависимость напряженности поля ЭМИ от времени близка по форме одному периоду синусоиды с длительностью $T=100 \mathrm{ps}$, соответственно средняя мощность излучения приблизительно в два раза меньше пиковой. Таким образом, энергия излучения изотропного источника равна $Q_{0}=P_{m} T / 2=1.8 \mathrm{~J}$. Так как наш источник не является изотропным, необходимо учесть угловое распределение излучения. С точностью до множителя порядка единицы угловая расходимость излучения $\vartheta \sim \lambda / D$, где $\lambda=3 \mathrm{~cm}-$ характерная длина волны излучения, $D=9 \mathrm{~cm}-$ диаметр излучающей области. Телесный угол, в который излучается основная доля энергии, равен $\sim \vartheta^{2}$, соответственно излученная энергия $Q=Q_{0}(\lambda / D)^{2} /(4 \pi)=0.016 \mathrm{~J}$. Эффективность излучателя, определенная как отношение энергии излучения к энергии, запасенной в межэлектродном зазоре, равна $Q / Q_{C}=0.08$.

С использованием дискретного преобразования Фурье напряженности поля $E(t) \rightarrow E(f)$ вычислена спектральная плотность энергии излучения $W \propto|E(f)|^{2}$, показанная на рис. 5-7. При увеличении напряжения на межэлектродном зазоре растут значения средней часто-

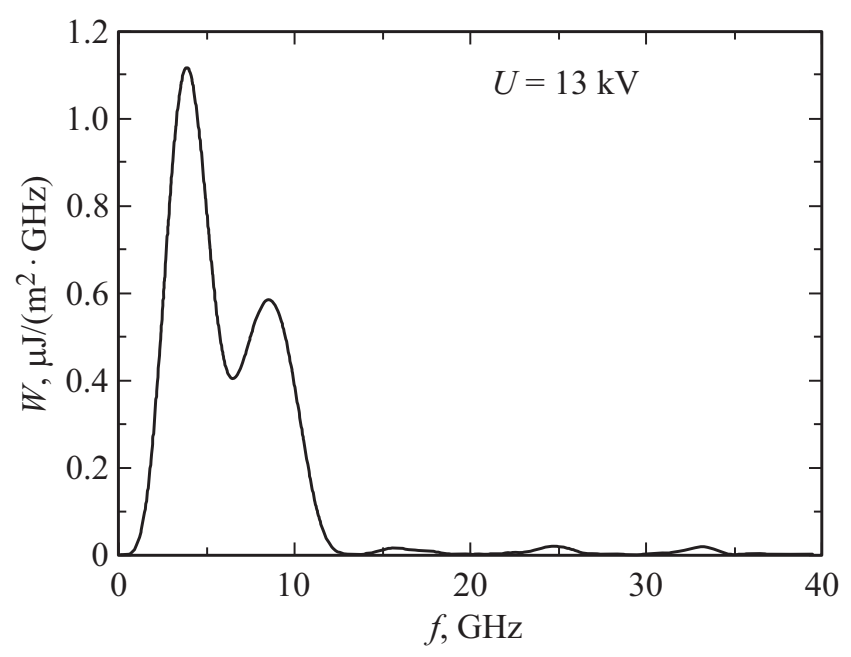

Рис. 5. Спектральная плотность энергии излучения при напряжении на межэлектродном зазоре $13 \mathrm{kV}$.

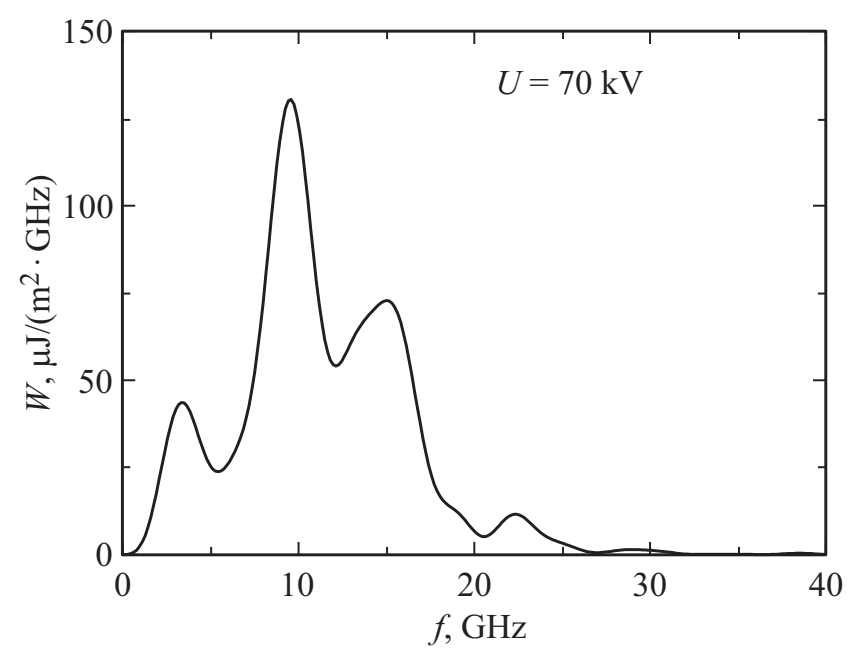

Рис. 6. Спектральная плотность энергии излучения при напряжении на межэлектродном зазоре $70 \mathrm{kV}$. 


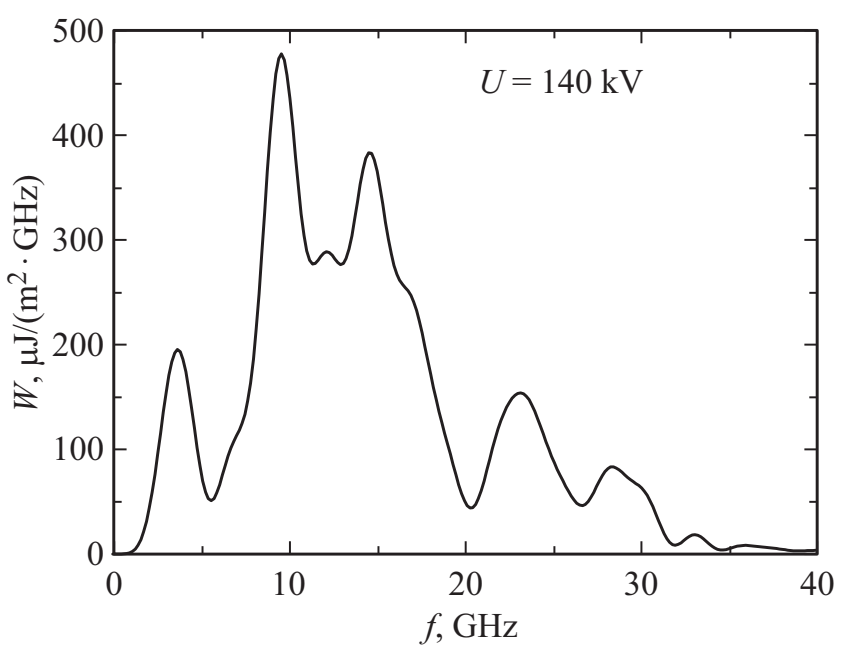

Рис. 7. Спектральная плотность энергии излучения при напряжении на межэлектродном зазоре $140 \mathrm{kV}$.

Зависимость частоты максимума спектра излучения $f_{m}$ и средней Частоты $f_{a}-$ от напряжения $U$ на межэлектродном зазоре

\begin{tabular}{l|c|c|c|c|c|c|c|c}
\hline$U, \mathrm{kV}$ & 13 & 35 & 50 & 70 & 90 & 110 & 130 & 140 \\
\hline$f_{m}, \mathrm{GHz}$ & 3 & 9 & 9.4 & 9.6 & 9.6 & 9.6 & 9.6 & 9.6 \\
\hline$f_{a}, \mathrm{GHz}$ & 6.5 & 8.6 & 10.2 & 11.3 & 12.7 & 13.9 & 14.2 & 14.6
\end{tabular}

ты спектра $f_{a}=\int_{0}^{\infty} f W(f) d f / \int_{0}^{\infty} W(f) d f$, приведенные в таблице. Из приведенных рисунков видно, что кривая спектральной плотности энергии имеет локальные максимумы и минимумы. Сравнение со спектрами, вычисленными для разных значений напряжения питания, показывает, что положение локальных экстремумов слабо изменяется при изменении напряжения, а изменяется отношение амплитуд этих экстремумов. В результате этого при увеличении напряжения питания от 34 до $140 \mathrm{kV}$ растет средняя частота спектра, а частота максимума спектра (см. таблицу) остается постоянной.

\section{Заключение}

Разработана конструкция и технология изготовления вакуумного фотодиода с анодом на входном сапфировом окне, сурьмяно-цезиевым фотокатодом диаметром $9 \mathrm{~cm}$ и межэлектродным зазором $0.3 \mathrm{~cm}$. При напряжении между анодом и катодом $140 \mathrm{kV}$ электродинамический потенциал излучателя составил $\approx 1050 \mathrm{kV}$, а эффективность излучателя, определенная как отношение энергии излучения к энергии, запасенной в межэлектродном зазоре, - 0.08. При увеличении напряжения питания от 13 до $140 \mathrm{kV}$ средняя частота спектра излучения увеличилась от 6.5 до $14.6 \mathrm{GHz}$.

\section{Благодарности}

Авторы благодарят Б.С. Щамхалову, С.Ю. Карташова, Т.В. Листкова, Г.А. Тюпаева и Е.Н. Миргородскую за обсуждение работы и изготовление экспериментальных образцов вакуумных фотодиодов.

\section{Финансирование работы}

Работа выполнена в рамках государственного задания.

\section{Конфликт интересов}

Авторы заявляют, что у них нет конфликта интересов.

\section{Список литературы}

[1] Ю.Н. Лазарев, П.В. Петров. Письма в ЖЭТФ, 60 (9), 625 (1994). [Yu.N. Lazarev, P.V. Petrov. JETP Lett., 60 (9), 634 (1994).]

[2] Ю.Н. Лазарев, П.В. Петров. ЖЭТФ, 115 (5), 1689 (1999).[Yu.N. Lazarev, P.V. Petrov. JETP, 88 (5), 926 (1999). DOI:10.1134/1.558873]

[3] A.V. Bessarab, A.A. Gorbunov, S.P. Martynenko, N.A. Prudkoy. IEEE Trans. on Plasma Sci., 32 (3), 1400 (2004). DOI:10.1109/TPS.2004.829825

[4] А.В. Бессараб, С.Г. Гаранин, С.П. Мартыненко, Н.А. Прудкой, А.В. Солдатов, В.А. Терехин, Ю.А. Трутнев. ДАН, 411 (5), 609 (2006). [A.V. Bessarab, S.G. Garanin, S.P. Martynenko, N.A. Prudkoy, A.V. Soldatov, V.A. Terekhin, Yu.A. Trutnev. Dokl. Phys., 51 (12), 651 (2006). DOI:10.1134/S1028335806120044]

[5] А.А. Кондратьев, Ю.Н. Лазарев, А.В. Потапов, А.С. Тищенко, Е.В. Заволоков, И.А. Сорокин. ДАН, 438 (5), 615 (2011). [A.A. Kondrat'ev, Yu.N. Lazarev, A.V. Potapov, A.S. Tishchenko, E.V. Zavolokov, I.A. Sorokin. Dok1. Phys., 56 (6), 314 (2011). DOI:10.1134/S1028335811060085]

[6] Ю.Н. Лазарев. Патент РФ № 2488909 (2013).

[7] Н.А. Пхайко, А.В. Потапов, А.А. Кондратьев. Патент РФ № 2668271 (2017).

[8] W.M. Haynes, Editor-in-Chief. CRC Handbook of Chemistry and Physics (CRC Press, 2014-2015) 95th edition.

[9] А.Ф. Аккерман, Ю.М. Никитушев, В.А. Ботвин. Решение методом Монте-Карло задач переноса быстрых электронов в веществе (Изд-во Наука Казахской ССР, АлмаАта, 1972) 